Exploratory laparotomy revealed the fistula opening internally at the isthmus of the uterus. At the isthmus the uterus was perforated and fetal remnants in the form of a few long bones were lying outside. A loop of the small bowel was densely adherent at this site which perforated during separation. There was no evidence of regional ileitis or endometriosis. Abdominal hysterectomy and resection and anastomosis of the small bowel was carried out. (The couple had requested sterilizatinn.) The fistulous tract was excised. Histopathology revealed no evidence of endometriosis, Crohn's disease or tuberculosis. Postoperative recovery was uneventful and the external opening healed completely.

\section{Discussic „1}

A fistula is an abnormal communication between two epithelial surfaces. Fistulae are usually lined by granulation tissue but they can become epithelialized. Most fistulae originate from trauma or from some type of infectious process that disrupts the continuity of the tissues involved. Once a fistula is diagnosed the basic principle in the treatment is obliteration of the primary opening of fistulous tract. There is no non-surgical treatment for fistula. ${ }^{4}$

In this case the patient possibly developed uterine perforation leading to pelvic abscess extending to perinephric and right flank region due to septic abortion which were drained subsequently. Conceivably the uterine perforation with stenosis of the cervix due to interference led to communication with the right flank and drainage through this area gave rise to the uterocutaneous fistula. Injection of contrast through the fistulous opening permitted an accurate diagnosis and extirpation of the uterus produced a cure.

3. Silva, P.D., Richmond, J.A. \& Lobo, R.A. Diagnosis and management of a tuberculous tuboappendiceal fistula. Am J Obstet Gynecol 1988, 159: 440-441.

4. Nova, P.F. Operative principles of fistula treatment. In: Nora P.F. (ed.) Operative Surgery Principles and Techniques, 2nd edn. Lea \& Febiger, Philadelphia, 1974, pp. 508-516.

. Arthur, C.W., Herman, M. \& Norber, R.B. Tubocutaneous fistula. Am J Obstet Gynecol 1982, 144: 109-110.

\title{
Type IV renal tubular acidosis associated with Alport's syndrome
}

\author{
Ružena Tkáčová, R. Roland, A. Böör ${ }^{1}$, Anna Kováčová ${ }^{2}$, Ivica Lazúrová ${ }^{3}$, \\ I. Tkáč ${ }^{4}$ T. Hildebrand and P. Sefara
}

Department of Internal Medicine I, and Departments of ${ }^{1}$ Pathological Anatomy, ${ }^{2}$ Biochemistry, ${ }^{3}$ Internal
Medicine II, and ${ }^{4}$ Internal Medicine IV, University Hospital, Trieda SNP 1,040 66 Košice, Slovakia

Summary: A case of hereditary nephritis with mild reduction of renal function associated with renal tubular acidosis type IV is described. The patient was admitted with life-threatening hyperkalaemia. To our knowledge, type IV renal tubular acidosis has not been reported previously in association with Alport's syndrome in an adult patient.

Correspondence: R. Tkáčová, M.D., Department of Internal Medicine I, Medical Faculty, Šafárik University, Trieda SNP 1, 04066 Košice, Slovakia.

Accepted: 4 March 1993

\section{Introduction}

Hereditary nephritis or Alport's syndrome is a heterogeneous group of inherited abnormalities of 
basement membranes which may result in renal failure, defective hearing and lens abnormalities. ${ }^{1}$ Recently, a patient with previously diagnosed perceptive deafness presented with hyperkalaemia of $9.5 \mathrm{mmol} / \mathrm{l}$, and was found to have mild reduction of glomerular filtration rate (GFR), and ultrastructural changes of glomerular basement membranes (GBM). Type IV renal tubular acidosis (RTA) was diagnosed by urine examination after acid loading. There are reports of this tubular dysfunction in children with nerve deafness, ${ }^{2,3}$ but we have found no report on type IV RTA associated with Alport's syndrome in an adult patient.

\section{Case report}

A 38 year old man of Gypsy origin was admitted to hospital in February 1992 with progressive muscular weakness, abdominal pain and vomiting for 5 days. In his family history, sudden death had occurred in two brothers and one sister, apparently as a result of a renal disease. The patient's history revealed a suggestion of Alport's syndrome in 1987 during hospitalization in a district hospital, based on the confirmation of defective hearing and microscopic haematuria; serum potassium levels were up to $6.4 \mathrm{mmol} / \mathrm{l}$ at that time.

On admission, he had a pulse rate of 60 beats/ minute, and systolic blood pressure of $100 \mathrm{mmHg}$. Physical examination revealed asthenia, muscular weakness, and diffuse abdominal tenderness. His jugular venous pressure was $6 \mathrm{~cm} \mathrm{H}_{2} \mathrm{O}$. There were $14 \mathrm{~mm}$ high $T$ waves in $V_{2}-V_{3}$ leads on the electrocardiogram. Laboratory investigations showed extremely high serum potassium level $(9.5 \mathrm{mmol} / \mathrm{l})$, white blood cell count (WBC) $19.1 \times 10^{9} / 1$, haemoglobin $131 \mathrm{~g} / \mathrm{l}$, creatinine 155 $\mu \mathrm{mol} / \mathrm{l}$, urea $11.2 \mathrm{mmol} / \mathrm{l}$, sodium level $136 \mathrm{mmol} / \mathrm{l}$, and phosphorus level $1.46 \mathrm{mmol} / \mathrm{l}$. The laboratory evidence of hyperchloraemic metabolic acidosis with blood $\mathrm{pH} 7.287$, base excess $-8.3 \mathrm{mmol} / \mathrm{l}$, $\mathrm{PCO}_{2} 4.97 \mathrm{kPa}$, bicarbonate level $17.2 \mathrm{mmol} / \mathrm{l}$, and serum chloride level of $113 \mathrm{mmol} / \mathrm{l}$ was present.

Haemodialysis was performed three times, each for 3 hours duration, within the first 24 hours. Other therapeutic methods were not considered in the period of life-threatening hyperkalaemia. After haemodialysis sessions serum potassium level decreased to $4.9 \mathrm{mmol} / 1$, and $\mathrm{T}$ waves to $5 \mathrm{~mm}$. No hypotensive episodes occurred during haemodialysis, and systolic blood pressure remained $100-110 \mathrm{mmHg}$ also in the next period at hospital. Consequently, the patient was given treatment with frusemide at the dose of $20 \mathrm{mg}$ and $\mathrm{NaHCO}_{3}$ of $1,500 \mathrm{mg}$ per day, resulting in serum potassium levels in the range of $4.4-5.3 \mathrm{mmol} / \mathrm{l}$. The patient was stable 6 months after discharge from hospital.

\section{Investigations}

Daily urine was $1,200 \mathrm{ml}$, creatinine clearance was $0.78 \mathrm{ml} / \mathrm{second}$. Urinalysis showed haematuria ${ }_{C}$ (400 million erythrocytes in Addis sediment) with no white cells, casts or proteins. Natriuresis was $\stackrel{\vec{\rho}}{\rightarrow}$ $93 \mathrm{~mol} / 24$ hours, urine potassium excretion (11-18 mmol/24 hours) were decreased, and cal- 흘 cium excretion $(0.7 \mathrm{mmol} / 24$ hours $)$, phosphorus $\frac{\bar{\sigma}}{\sigma}$ excretion revealed increased values $(32.4 \mathrm{mmol} / 24 \stackrel{\varnothing}{\propto}$ hours). Dietary phosphorus intake was up to $1.6 \mathrm{~g} / 24$ hours.

The diagnosis of type IV RTA associated with Alport's syndrome was suspected. The urinalysis $\vec{\omega}$ dynamic tests showed the basal urine $\mathrm{pH}$ value $5.7, \stackrel{\sim}{\circ}$ the administration of $10 \%$ calcium chloride at the 8 dose of $57 \mathrm{ml}$ led to the urine $\mathrm{pH}$ of 5.14 , fractional 3 . excretion of bicarbonate was $0.08 \%$. Acid loading 8 test revealed normal excretion of phosphates $\infty$ $\left(550 \mathrm{nmol} / \mathrm{second} / 1.73 \mathrm{~m}^{2}\right.$, normal $>300 \mathrm{nmol} / \vec{\sigma}$ second $/ 1.73 \mathrm{~m}^{2}$ ) whereas ammonium excretion was inadequately low $\left(137 \mathrm{nmol} / \mathrm{second} / 1.73 \mathrm{~m}^{2}\right.$, nor- $-\omega$ mal $>500 \mathrm{nmol} / \mathrm{second} / 1.73 \mathrm{~m}^{2}$ ). Basal plasma 웅 renin activity (PRA) was $0.9 \mathrm{ng} / \mathrm{ml} /$ hour (normal $0.5-1.5 \mathrm{ng} / \mathrm{ml} /$ hour), aldosterone (ALD) was $\bigcirc$ $25.55 \mathrm{pg} / \mathrm{ml}$ (normal $7.5-160 \mathrm{pg} / \mathrm{ml}$ ), atrial nat- $\overrightarrow{0}$ riuretic factor (ANF) was $5.74 \mathrm{pg} / \mathrm{ml}$ (normal $\stackrel{\circ}{\square}$ $2-7 \mathrm{pg} / \mathrm{ml}$ ). All hormonal activities were measureg $\vec{\theta}$ using radioimmunoassay analysis. After posturi stimulation combined with frusemide at the dose of $80 \mathrm{mg}$ the following hormone values were measu ed: PRA, $0.98 \mathrm{ng} / \mathrm{ml} / \mathrm{hour}$; ALD, $47.21 \mathrm{pg} / \mathrm{ml}$; ANF, $2.6 \mathrm{pg} / \mathrm{ml}$. The basal cortisol level was $750 \mathrm{nmol} / 1,120$ minutes after ACTH administration (Synacthen, CIBA) at the dose of $2 \mathrm{mg}$ it $\stackrel{\unrhd}{\unrhd}$ increased up to $1,360 \mathrm{nmol} / 1$, and thus primary $\overrightarrow{\vec{O}}$ hypocorticism was excluded.

Audiogram confirmed perceptive deafness affecting both ears. A computed tomography scan of adrenals demonstrated no pathological changes. $\bar{O}$ On ultrasound both kidneys appeared to have 3 . normal size (left: $95 \times 40 \mathrm{~mm}$, right: $94 \times 45 \mathrm{~mm}$ ) with parenchyma thickness of $14 \mathrm{~mm}$; no pathological echo structures were found. At light $ᄋ$ microscopic examination kidney biopsy showed nonspecific changes with pronounced interstitial $ᄋ$ fibrosis, some areas of canalicular atrophy, and $\supset$ arteriolosclerotic changes of the arterioles with their focal fibrinoid dystrophy. Ultrastructural features of the glomeruli showed segmental mesan- $\sigma$ gial proliferation, segmental sclerosis and epithelial $\tilde{O}$ proliferation. GBM thickness varied significantly, $\underset{\omega}{N}$ and some areas of extremely thin GBM were found $\sigma$ (Figure 1).

\section{Discussion}

The diagnosis of Alport's syndrome in the present case report was based on the criteria according to 


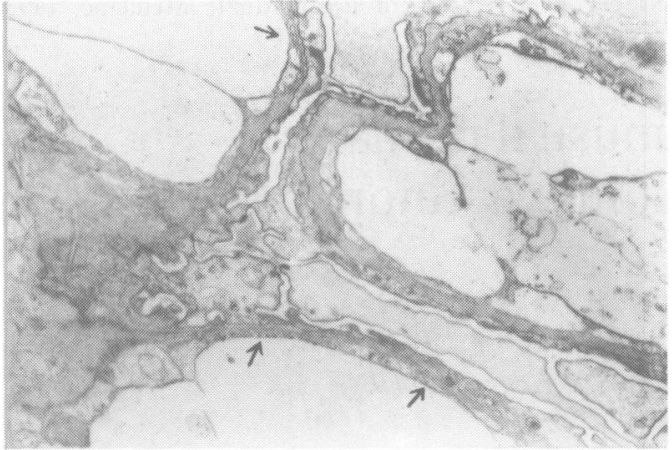

Figure 1 Marked focal thinning of the capillary basement membranes (arrows) and foot process fusion on the visceral epithelial cells. Electron microscopy (original magnification $\times 14,000)$.

Genova et al. ${ }^{4}$ : (1) perceptive deafness; (2) ultrastructural abnormalities of GBM; (3) positive family history. This syndrome represents a heterogeneous group of inherited abnormalities of basement membranes that may result in progressive renal failure. ${ }^{1}$ It is suggested to be a result of mutations in an X-chromosome-encoded basement membrane collagen chain, and its phenotypic heterogenity probably arises from allelic mutations at a single genetic locus. ${ }^{5}$ Thinning and splitting of the GBM are assumed to be characteristic, but nonspecific, ultrastructural alterations in Alport's syndrome. ${ }^{6}$ Extremely thin GBM areas were also found in our patient, and according to Rumpelt this is the basic lesion representing a persistent embryonal status of the lamina densa in Alport's syndrome. ${ }^{6}$ Recently, some variants of Alport's syndrome were described including oesophageal, tracheobronchial and genital leiomyomatosis, and

\section{References}

1. Savige, J.A. The gene corresponding to the putative Goodpasture antigen is present in Alport's syndrome. Clin Exp Immunol 1991, 85: 236-239.

2. Ronconi, G.F., Pesenti, P., Usai, A.E., Ronconi, M. \& Soffiati, G. Distal renal tubular acidosis with nerve deafness. Pediatr Med Chir 1984, 6: 549-552.

3. Santos, F., Rey, C., Malaga, S., Rodriguez, L.M. \& Orejas, G. The syndrome of renal tubular acidosis and nerve deafness. Discordant manifestations in dizygotic twin brothers. Pediatr Nephrol 1991, 5: 235-237.

4. Genova, R., Polisseni, E., Agazzini, E. \& Maffei, S. Alport syndrome: 15-year follow-up in 28 cases. Pediatr Med Chir 1986, 8: $331-340$.

5. Kashtan, C.E., Kleppel, M.M., Butkowski, R.J., Michael, A.F. \& Fish, A.J. Alport syndrome, basement membranes and collagen. Pediatr Nephrol 1990, 4: 523-532.

6. Rumpelt, H.J. Alport's syndrome: specificity and pathogenesis of glomerular basement membrane alterations Pediatr Nephrol 1987, 1: 422-427.

7. Grunfeld, J.P., Grateau, G., Noel, L.H. et al. Variants of Alport's syndrome. Pediatr Nephrol 1987, 1: 419-421.

8. Rabushka, L.S., Fishman, E.K., Kuhlman, J.E. \& Hruban, R.H. Diffuse esophageal leiomyomatosis in a patient with Alport syndrome: CT demonstration. Radiology 1991, 179: $176-178$ hereditary macrothrombocytopenia., ${ }^{7,8}$ However, no signs of these pathological conditions were present in our case.

Type IV RTA is a syndrome of tubular dysfunction manifested clinically by persistent hyperkalaemia and metabolic acidosis that occurs usually in patients with mild to moderate chronic renal failure. ${ }^{9}$ Hyperkalaemia might contribute to the acidosis by limitating urinary buffer, but the primary defect is the reduced mineralocorticoid effect on hydrogen ion secretion. ${ }^{10}$ Apart from primary hypocorticism, pseudohypoaldosteronism resulting in hyperchloraemic metabolic acidosis with hyperkalaemia may occur in different pathological conditions, such as diabetic nephropathy, ${ }^{11}$ idiopathic interstitial nephritis, ${ }^{12}$ chronic pyelonephritis, ${ }^{13}$ and in obstructive uropathy. ${ }^{14} \mathrm{~A}$ case of type I (hypokalaemic) RTA was described in a male child with neural deafness in whom addition of $\mathrm{NaHCO}_{3}$ and potassium to diet improved physical condition. ${ }^{2}$ Recently, discordant manifestations of RTA syndrome combined with nerve deafness in dizygotic twins were reported. ${ }^{3}$ However, for the first time to our knowledge, a case of Alport's syndrome in an adult man has been reported in association with type IV RTA resulting in hyperkalaemia. Our patient did not increase $\mathrm{NH}_{4}$ secretion after acid loading adequately, whereas his PRA, ALD and ANF levels were within the physiological ranges.

This case illustrates that, though rare, RTA type IV has to be considered in Alport's syndrome with mild reduction of renal functions. Once considered, all available diagnostic means have to be used in order to reach a correct diagnosis and treatment and thus to prevent life-threatening hyperkalaemia.

9. Schambelan, M. \& Sebastian, A. Type IV renal tubular acidosis: pathogenetic role of aldosterone deficiency and hyperkalemia. Nephrologie 1985, 6: 135-137.

10. Licht, J.H., Amundson, D., Hsueh, W.A. \& Lombardo, J.V. Familiar hyperkalaemic acidosis. $Q J$ Med 1985, 54: $161-176$.

11. Grande, J., Macias, J.F., Miralles, J. \& Tabernero, J.M Plasma renin activity, plasma aldosterone and distal urinary acidification in diabetics with chronic renal failure. Proc EDTA 1985, 21: 801-807.

12. Kristjansson, K., Laxdal, R. \& Ragnarsson, J. Type 4 renal tubular acidosis (subtype 2) associated with idiopathic interstitial nephritis. Acta Pediatr Scand 1986, 75: 1051-1054.

13. Sakamoto, H., Umetani, N., Kobayashi, Y., Okubo. M. Marumo, F. \& Kikawada, R. A case of reversible hyperkalemic distal renal tubular acidosis associated with chronic pyelonephritis. Nippon Naika Gakkai Yasshi 1986, 75: $1650-1656$

14. Korman, S., Borochovitz. Z. \& Hochberg, Z. Distal renal tubular acidosis with hyperkalemia due to obstructive uropathy. Harefuah 1984, 107: 62-64. 